\title{
Coronary anatomy in patients with various manifestations of three vessel coronary artery disease
}

\author{
ARSHED A QUYYUMI, HUSSAIN K AL-RUFAIE, ECKHARDT G J OLSEN, \\ KIM M FOX
}

From the National Heart Hospital, London

SUMMARY The histology of coronary arteries was compared in patients with rest and effort angina. The arteries came from six patients with three vessel disease who died within four weeks of arteriography and ambulatory ST segment monitoring. Sections of all macroscopically visible arteries were taken every $5 \mathrm{~mm}$ and examined histologically. Episodes of ST segment depression had occurred on exertion in two patients, during exertion and rest (nocturnal) in two, and two patients had had no episodes of ST segment depression during ambulatory monitoring. Concentric $(29 \%)$ or eccentric $(62 \%)$ intimal thickening due to atheroma or fibroelastic tissue was found in $91 \%$ of sections. All but two normal intimal sections $(1 \%)$ were found to be diseased in patients with ambulatory ST segment changes. Eccentric lesions with medial smooth muscle preservation in areas without intimal thickening, where further luminal narrowing could occur due to increases in smooth muscle tone, were found in $15 \%$ of sections. But these areas were not found in the proximal $3.5 \mathrm{~cm}$ of any of the major coronary arteries of the two patients with rest and effort ischaemia. Spasm could not have caused total occlusion in any of these arteries because the lumen was splinted by the lesion. There was no difference in mean luminal narrowing between patients with exertional and rest ischaemia and exertional ischaemia only (mean $74 \%$ ), but mean luminal narrowing was lower in patients with no ambulatory episodes of ST segment change (39\%). Thus medial smooth muscle spasm was unlikely to have caused occlusion in patients with ambulatory ST segment changes, although it could have altered lumen diameter. There were no histological differences in the coronary arteries of patients with rest or effort induced myocardial ischaemia.

When atheromatous coronary artery disease is present, myocardial ischaemia may occur on exertion, or during effort and at rest, or may be undetectable. Episodes of ST segment depression or elevation are reliable and reproducible markers of myocardial ischaemia ${ }^{1}$ even when they are not associated with pain; ambulatory recordings of ST segment changes provide an accurate index of the frequency of episodes of rest and effort myocardial ischaemia during normal daily activities. ${ }^{23}$

Different mechanisms have been proposed for development of myocardial ischaemia in patients with coronary artery disease. It has been suggested that further narrowing of an atheromatous coronary artery due to smooth muscle spasm is responsible for rest and nocturnal angina, ${ }^{45}$ however, there have been no detailed comparative anatomical studies of

Requests for reprints to Dr Arshed A Quyyumi, National Heart Hospital, Westmoreland Street, London W1M 8BA.

Accepted for publication 27 June 1985 the coronary arteries in such patients. This study was designed to investigate the coronary anatomy of patients with various manifestations of three vessel coronary artery disease.

\section{Patients and methods}

Patients-Six patients, five male and one female aged 46 to 69 years, who died within four weeks of coronary arteriography, exercise testing, and ambulatory ST segment monitoring were investigated. Three patients (cases 1-3) complained of rest and exertional angina including nocturnal angina, whereas the others (cases 4-6) complained of exertional angina only (Table 1). The resting electrocardiogram showed evidence of old myocardial infarction ( $Q$ waves) in all except one patient (case 5). Symptom limited maximal treadmill exercise tests were performed according to the modified Bruce protocol in five patients but one patient (case 2) who had rest pain associated with ST segment 
Table 1 Characteristics of patients with three vessel coronary artery disease

\begin{tabular}{|c|c|c|c|c|c|c|c|}
\hline \multirow[t]{2}{*}{ Patient } & \multirow{2}{*}{$\begin{array}{l}\text { Exercise duration } \\
\text { to } 1 \text { mm } S T \\
\text { depression (min) }\end{array}$} & \multirow{2}{*}{$\begin{array}{l}\text { Previoius } \\
\text { myocardial } \\
\text { infarction }\end{array}$} & \multirow{2}{*}{$\begin{array}{l}\text { Ambulatory } S T \\
\text { segment changes }\end{array}$} & \multirow{2}{*}{$\begin{array}{l}\text { Site of terminal } \\
\text { myocardial } \\
\text { infarction }\end{array}$} & \multirow{2}{*}{$\begin{array}{l}\text { Heart } \\
\text { weight }(g)\end{array}$} & \multicolumn{2}{|l|}{ No of sections } \\
\hline & & & & & & $\begin{array}{l}\text { Right coronary } \\
\text { artery }\end{array}$ & $\begin{array}{l}\text { Left coronary } \\
\text { artery }\end{array}$ \\
\hline 1 & 3 & Inferior & Daytime and & Anterior & 575 & 25 & 36 \\
\hline 2 & Not done & Inferior & $\begin{array}{l}\text { nocturnal } \\
\text { Daytime and } \\
\text { nocturnal }\end{array}$ & Inferolateral & 340 & 29 & 25 \\
\hline $\begin{array}{l}3 \\
4 \\
5 \\
6\end{array}$ & $\begin{array}{l}3 \\
2 \\
\text { Negative } \\
9\end{array}$ & $\begin{array}{l}\text { Inferior } \\
\text { Inferolateral } \\
\overline{\text { Inferior }}\end{array}$ & $\begin{array}{l}\text { Daytime only } \\
\text { Daytime only } \\
\text { Nil } \\
\text { Nil }\end{array}$ & $\begin{array}{l}\text { Subendocardial } \\
\text { Anterior } \\
\text { Anterior } \\
\text { Inferolateral }\end{array}$ & $\begin{array}{l}550 \\
538 \\
579 \\
580\end{array}$ & $\begin{array}{l}46 \\
22 \\
50 \\
33\end{array}$ & $\begin{array}{l}30 \\
42 \\
52 \\
54\end{array}$ \\
\hline
\end{tabular}

changes on the electrocardiogram was not exercised. All except one patient (case 5) developed ST segment depression of $1 \mathrm{~mm}$ or more during the stress test (Table 1).

All patients died after acute myocardial infarction; two (cases 2 and 4 ) before operation and the remain-

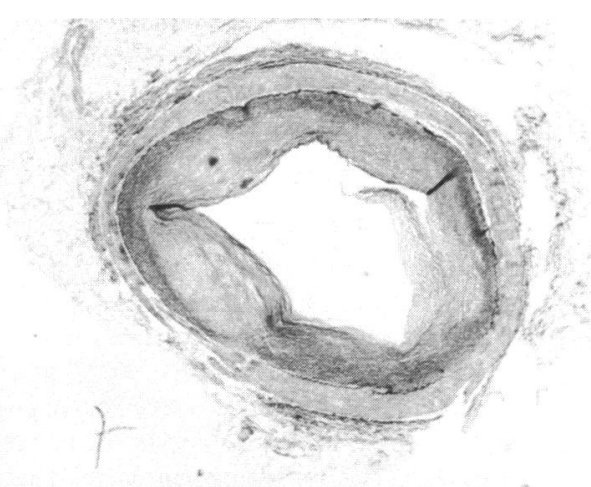

Fig. 1 Photomicrograph of typical section of coronary artery demonstrating concentric intimal thickening due to fibroatheromatous tissue. Original magnification $\times 25$.

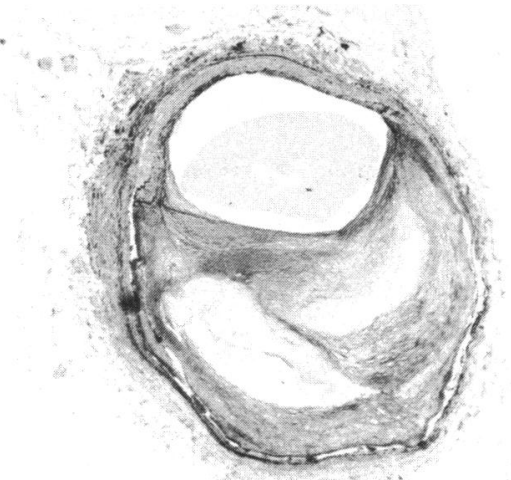

Fig. 2 Photomicrograph of section of coronary artery demonstrating eccentric fibroatheromatous intimal thickening without involvement of the remaining intima and with smooth muscle preservation. Original magnification $\times 25$. ing four patients after coronary artery bypass surgery. Investigations were performed at least three weeks before death in all patients.

Ambulatory ST segment monitoring-Forty eight hour ambulatory monitoring was performed when patients were on no anti-anginal treatment other than sublingual glyceryl trinitrate which was given for pain. An electrocardiogram was recorded continuously through two bipolar precordial leads (CM5 and a lead resembling lead II) on a frequency modulated recorder (Oxford Medilog II). During playback, the number, magnitude, and duration of the episodes of significant ST segment depression ( $\geqslant 1 \mathrm{~mm}$ planar or downsloping occurring $0.08 \mathrm{sec}-$ onds after the QRS complex) and ST segment elevation ( $\geqslant 1 \mathrm{~mm}$ elevation of the $\mathrm{J}$ point) were noted, whether or not they were accompanied by pain. Patients 1 and 2 had episodes of ST depression during daytime exertion and at rest; patients 3 and 4 had episodes during the daytime on exertion only, and patients 5 and 6 had no ambulatory ST segment changes in 48 hours of continuous monitoring (Table 1).

Cardiac catheterisation-Conventional left ven-

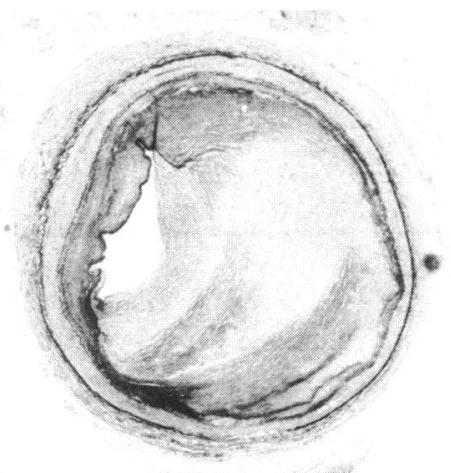

Fig. 3 Photomicrograph of section of coronary artery with circumferential fibroatheromatous intimal thickening where the bulk of the lesion is eccentric. Original magnification $\times 25$. 
triculography and coronary arteriography were performed in five patients (cases 1, 3-6). Patient 2 died from acute myocardial infarction before arteriography was performed but ambulatory monitoring had been performed three weeks before myocardial infarction. Severe three vessel obstructive coronary artery disease was observed in all five patients who had angiocardiography. Only one patient (case 4) had angiographically visible occlusion of the distal third of the left anterior descending artery, with retrograde filling from a diseased right coronary artery. All other patients had one or more severe stenoses but no evidence of occlusion was seen at angiography. Left ventriculography showed hypokinesia of the inferior wall, with pronounced reduction in ejection fraction $(<40 \%)$ in two patients (cases 3 and 4).

Histopathology-At necropsy the hearts were fixed in formol saline. All visible coronary arteries were dissected intact from the heart, labelled, and sectioned at every $0.5 \mathrm{~cm}$. Sections were embedded in paraffin and stained with haematoxylin and eosin and elastic van Gieson stains. Areas of concentric intimal thickening by either fibroelastic or atheromatous tissue were noted (Fig. 1). Areas of eccentric narrowing where there was medial smooth muscle preservation without intimal thickening (Fig. 2) and areas where eccentric fibroatheromatous deposition was accompanied with circumferential intimal thickening (Fig. 3) were also noted. The degree of narrowing of each segment was measured and expressed as a ratio of lumen diameter to the distance between the internal elastic laminae. Two measurements at $90^{\circ}$ to each other were obtained. This method overcame substantially the difficulties posed by distortion of the sections which were not fixed under pressure. Intraluminal thrombus was present in six sections from six arteries in five patients. This was fresh thrombus, however, and all these patients had died before or after operation from a myocardial infarction which was clearly a consequence of acute thrombosis. Data were analysed by Student's $t$ test for unpaired observations.

\section{Results}

Concentric and eccentric intimal thickening caused by atheroma or fibroblastic tissue that resulted in luminal narrowing was found in $91 \%$ of all the sections examined (Table 2). Normal coronary artery segments $(9 \%$ of total) were observed in only three patients (cases 1, 5 and 6). Only one $0.5 \mathrm{~cm}$ section of normal artery was seen in the left circumflex artery and the right coronary artery in patient 1 who had ST segment changes at rest and during exertion. The two patients (cases 5 and 6 ) without ambulatory ST segment changes had 11 and 20 sections of normal coronary arteries respectively, however, not more than two of these sections $(>1 \mathrm{~cm})$ were continuous. Thus, intimal thickening was present in nearly all the sections of macroscopically visible coronary arteries in the four patients with ambulatory ST segment changes (cases 1-4) whereas $16 \%$ of the sections examined in the two patients without ST segment changes was normal.

Intimal thickening where there was symmetrical atherosclerosis of the walls and a central lumen (Fig. 1) was seen in $29 \%$ of the sections examined ( $8 \%$ to $33 \%$ in individual patients) (Table 2). In $62 \%$ of the sections examined there were eccentric lesions, where most of atheromatous deposit was in one part of the wall, but in most of these lesions $(47 \%)$ there was also atheromatous or fibroelastic thickening in the intimal wall which was not involved in the eccentric lesions (Fig. 3). Eccentric lesions in which there was preservation of smooth muscle and absence of intimal thickening in the remaining wall were observed in $15 \%$ (range $12 \%-18 \%$ ) of the sections (Fig. 2). Thus, there was no significant difference in the distribution of the different types of lesions (concentric and eccentric with or without smooth muscle preservation) in patients with ST changes at rest or

Table 2 Mean narrowing of luminal diameter and histology of $0.5 \mathrm{~cm}$ sections of coronary arteries from patients with ambulatory $S T$ segment changes of varying severity

\begin{tabular}{|c|c|c|c|c|c|c|}
\hline \multirow[t]{2}{*}{ Patients } & \multirow{2}{*}{$\begin{array}{l}\text { Ambulatory } S T \\
\text { changes }\end{array}$} & \multirow{2}{*}{$\begin{array}{l}\text { Mean narrowing of } \\
\text { luminal diameter }(\%)\end{array}$} & \multicolumn{3}{|c|}{$\%$ of sections with intimal thickening } & \multirow[t]{2}{*}{ Normal } \\
\hline & & & Concentric & $\begin{array}{l}\text { Eccentric } \\
\text { (total) }\end{array}$ & $\begin{array}{l}\text { Eccentric with } \\
\text { smooth muscle } \\
\text { preserved }\end{array}$ & \\
\hline 1 and 2 & $\begin{array}{l}\text { Daytime and } \\
\text { nocturnal }\end{array}$ & $\begin{array}{l}\text { LCA (78) } \\
\text { RCA (70) }\end{array}$ & 28 & 71 & 14 & 1 \\
\hline 3 and 4 & Daytime only & $\begin{array}{l}\text { LCA (75) } \\
\text { RCA (74) }\end{array}$ & 16 & 84 & 18 & 0 \\
\hline 5 and 6 & Nil & $\begin{array}{l}\text { LCA (31) } \\
\text { RCA (47) }\end{array}$ & 29 & 55 & 12 & 16 \\
\hline
\end{tabular}

LCA, left coronary artery; RCA, right coronary artery. 
Table 3 Mean narrowing of luminal diameter in sections from the proximal $3 \mathrm{~cm}$ of the coronary arteries and the distance from the coronary ostia of the first sections in which intimal thickening is absent and medial smooth muscle is preserved

\begin{tabular}{|c|c|c|c|}
\hline Patients & Ambulatory $S T$ changes & $\begin{array}{l}\text { Mean proximal luminal } \\
\text { narrowing }(\%)\end{array}$ & $\begin{array}{l}\text { Distance of eccentric lesion with smooth muscle } \\
\text { preservation from ostium }(\mathrm{cm})\end{array}$ \\
\hline 1 & $\begin{array}{l}\text { Daytime and } \\
\text { nocturnal }\end{array}$ & $\begin{array}{l}\text { LCA }(69) \\
\text { RCA }(63)\end{array}$ & $\underset{\mathrm{Nil}}{4}$ \\
\hline 2 & $\begin{array}{c}\text { nocturnal } \\
\text { Daytime and } \\
\text { nocturnal }\end{array}$ & $\begin{array}{l}\text { RCA (63) } \\
\text { LCA (86) } \\
\text { RCA (90) }\end{array}$ & $\begin{array}{l}\text { Nil } \\
4 \cdot 5 \\
5\end{array}$ \\
\hline 3 & Daytime only & $\begin{array}{l}\text { LCA (73) } \\
\text { RCA (81) }\end{array}$ & $0 \cdot 5$ \\
\hline 4 & Daytime only & LCA (82) & $\begin{array}{r}5 \cdot 5 \\
5.5\end{array}$ \\
\hline 5 & Nil & LCA (39) & $5 \cdot 5$ \\
\hline 6 & Nil & $\begin{array}{l}\text { RCA }(53) \\
\text { LCA }(64) \\
R C A(40)\end{array}$ & $\begin{array}{l}N 11 \\
2.5 \\
6.5\end{array}$ \\
\hline
\end{tabular}

LCA, left coronary artery; RCA, right coronary artery.

during exertion or in those without ambulatory ST segment changes (Table 2).

The diameter of the vessel lumen was narrowed by $2 \%$ to $100 \%$ in the sections with fibroatheromatous intimal deposition. There was occlusion of the lumen in seven arteries from five patients. In six arteries in these five patients a fresh thrombus occluded the lumen; whereas in the distal left anterior descending coronary artery of patient 4 there was an old organised thrombus. This was consistent with the coronary arteriographic findings in these patients in whom occlusion was only visible in the distal anterior descending coronary artery of patient 4 . The recent thrombi observed at necropsy were the cause of the myocardial infarctions immediately preceding death in all other patients.

Mean luminal narrowing was also calculated in the right and left coronary arterial trees in each patient (Table 2). This narrowing tended to be less pronounced (range $29 \%$ to $58 \%$ ) in patients with no ambulatory ST segment changes (cases 5 and 6) than in patients with ST segment changes (range $68 \%$ to $83 \%)(p>0.05)$. Mean luminal narrowing in patients with only exertional daytime episodes of ST depression (cases 3 and 4) was similar to that found in patients with effort and nocturnal angina (cases 1 and 2) (Table 2).

Examination of the proximal sections (first $3 \mathrm{~cm}$ ) of the main coronary arteries (Table 3 ) showed that the narrowing was more severe in patients with ambulatory ST segment changes than in patients without ST changes $(p<0.01)$. The site of sections with an eccentric lesion, a thin intima, and preservation of medial smooth muscle, where spasm could have altered lumen diameter was also noted. Only two patients (cases 3 and 6), neither of whom had ST segment changes at rest, had such lesions in the proximal $3.5 \mathrm{~cm}$ of any of the major coronary arteries (Table 3 ).

\section{Discussion}

Myocardial ischaemia can occur on exertion or at rest and during the night, and several mechanisms have been postulated to account for these different manifestations of angina. ${ }^{4-6}$ Myocardial blood supply is critically dependent on the diameter of the large conductance coronary arteries which offer minimal resistance to blood flow when they are of normal calibre. With normal perfusion pressure, narrowing of the luminal diameter to less than $1.0 \mathrm{~mm}$ has been shown to reduce considerably poststenotic blood flow, which falls dramatically if the lumen dimension is further reduced. ${ }^{7}$ In our study, patients with three vessel disease who had ambulatory ST segment changes (patients 1 to 4) had greater mean luminal narrowing than the two patients (cases 5 and 6) who had no ST segment changes. The severity of luminal narrowing was, however, similar in patients with rest and effort angina and those with the effort angina only, both in the proximal portions of the main coronary arteries and in all sections of visible coronary arteries.

Myocardial ischaemia at rest is usually regarded as being due to coronary spasm. ${ }^{4}$ Medial smooth muscle spasm could only occlude the lumen of entirely normal sections of the arteries. Even in sections of artery where there is an eccentric fibroatheromatous lesion, there are several reasons why spasm could not produce complete occlusion. Eccentric lesions splint the lumen and prevent total luminal occlusion, also medial smooth muscle destruction and replacement with fibrous tissue was common. Detailed examination of arteries in this study has demonstrated that almost all the normal sections were found in patients without myocardial ischaemia during normal daily activities as indicated by the absence of ambulatory ST segment changes. All but two sections of coronary arteries in one 
patient with nocturnal ST segment changes had either concentric or eccentric intimal thickening which precluded the possibility that smooth muscle spasm could totally occlude the lumen. The study thus emphasises that coronary spasm causing total luminal occlusion is unlikely to be the underlying mechanism of rest angina in patients with severe obstructive coronary artery disease.

Further reduction of an already compromised coronary lumen can, however, occur as a result of an increase in medial smooth muscle tone. ${ }^{8}$ Absence of intimal thickening and preservation of smooth muscle where spasm might conceivably have produced further luminal narrowing was found in only $15 \%$ of all sections and such sections were equally common in all groups of patients (Table 2). Hyperreactivity of such lesions, as shown by increased sensitivity to alpha adrenergic stimulation, has been suggested as a mechanism of precipitating rest angina, ${ }^{8}$ however, dynamic measurements were not made in this study. Sections where smooth muscle preservation and an eccentric atheromatous lesion were present never extended for more than $1 \mathrm{~cm}$ of the coronary artery. Also, none of these sections was found in the proximal $3.5 \mathrm{~cm}$ of any of the major coronary arteries in the two patients with nocturnal ST segment changes. One patient (case 5) with no ambulatory ST segment changes and one (case 3) with only daytime changes had such sections in the proximal $3 \mathrm{~cm}$ of the left coronary artery. Thus dynamic coronary stenosis due to medial spasm can only occur in small sections of very few coronary arteries; and it could not have occurred in the proximal portions of the major coronary arteries in patients who had frequent nocturnal ischaemia. Other factors such as platelet aggregation at sites of previous luminal narrowing may, however, also cause sudden reductions in coronary blood flow. ${ }^{9}$

Coronary arteriography in five patients showed total luminal obstruction of the distal left anterior descending coronary artery in only one patient. Thrombus, which was seen at necropsy to occlude the coronary lumen, was clearly the cause of death in these patients. We may have over or under estimated luminal narrowing in this study because sections were not fixed under pressure. ${ }^{10} \mathrm{We}$ attempted to overcome this difficulty by measuring narrowing of the luminal diameter as a percentage of the distance from opposite internal elastic laminae and by making two measurements at $90 \%$ to each other in each section. Furthermore, we did not attempt to calculate the absolute luminal diameter and we compared results in patients in whom the arteries were fixed and measured indentically and therefore were subject to the same degree of distortion.

Recent studies have demonstrated the importance of increases in heart rate that precede the onset of ST segment changes (not only during the day but also at night) in patients with coronary artery dis- ease. ${ }^{6}$ These increases in nocturnal myocardial oxygen consumption may be sufficient to precipitate ischaemia in these patients who have severe diffuse luminal narrowing. Dynamic changes in luminal diameter may not have to be invoked to explain the occurrence of nocturnal ischaemia in these patients.

Although all patients had angiographically established localised three vessel disease, detailed sectioning of coronary arteries every $0.5 \mathrm{~cm}$ highlighted the diffuseness of the atherosclerotic process. The extent of coronary artery disease has been reported to be underestimated by angiography ${ }^{1112}$ and detailed anatomical studies are required to evaluate the pathophysiology of coronary artery disease.

We thank the British Heart Foundation for their support.

\section{References}

1 Chierchia S, Lazzari M, Freedman B, Brunelli C, Maseri A. Impairment of myocardial perfusion and function during painless myocardial ischemia. $\mathcal{f} \mathrm{Am}$ Coll Cardiol 1983; 1: 924-30.

2 Selwyn AP, Fox KM, Eves M, Oakley D, Dargie H, Shillingford JP. Myocardial ischaemia in patients with frequent angina pectoris. $\mathrm{Br} \mathrm{Med} \mathcal{F} 1978$; ii: 1594-6.

3 Bragg-Remschell DA, Anderson CM, Winkle RA. Frequency response characteristics of ambulatory ECG monitoring systems and their implications for ST segment analysis. Am Heart $f$ 1982; 103: 20-31.

4 Maseri A, Severi S, De Nes M, et al. 'Variant' angina: one aspect of a continuous spectrum of vasospastic myocardial ischemia. Am $\mathcal{F}$ Cardiol 1978; 42: 1019-35.

5 Gorlin R. Role of coronary vasospasm in the pathogenesis of myocardial ischaemia and angina pectoris. Am Heart f 1982; 103: 598-603.

6 Quyyumi AA, Wright CA, Mockus LJ, Fox KM. Mechanisms of nocturnal angina pectoris: importance of increased mycardial oxygen demand in patients with severe coronary artery disease. Lancet 1984; i: 1207-9.

7 McMahan MM, Brown BG, Cukingnan R, et al. Quantitative coronary angiography: measurement of the 'critical' stenosis in patients with unstable angina and single-vessel disease without collaterals. Circulation 1979; 60: 106-13.

8 Brown BG. Coronary vasospasm. Observations linking the clinical spectrum of ischemic heart disease to the dynamic pathology of coronary atherosclerosis. Arch Intern Med 1981; 141: 716-22.

9 Folts JD, Crowell EB, Rowe GG. Platelet aggregation in partially obstructed vessels and its elimination with aspirin. Circulation 1976; 54: 365-70.

10 Davies MJ, Thomas A. Thrombosis and acute coronary-artery lesions in sudden cardiac ischemic death. N Engl F Med 1984; 310: 1137-40.

11 Arnett EN, Isner JM, Redwood DR, et al. Coronary artery narrowing in coronary heart disease: comparison of cineangiographic and necropsy findings. Ann Intern Med 1979; 91: 350-6.

12 Vlodaver Z, Frech R, Van Tassel RA, Edwards JE. Correlation of the antemortem coronary arteriogram and the postmortem specimen. Circulation 1973; 47: 162-9. 